\title{
PROJEKAT KONSTRUKCIJE AB ZGRADE U NOVOM SADU I UPOREDNA ANALIZA PRSLINA PREMA ,EN 1992“ I „PBAB '87“
}

\section{THE DESIGN OF RC BUILDING IN NOVI SAD WITH COMPARATIVE ANALYSIS OF THE CRACKS ACCORDING TO „EN 1992“ AND „PBAB '87““}

\section{Dragana Nerić, Fakultet tehničkih nauka, Novi Sad}

\section{Oblast - GRAĐEVINARSTVO}

Kratak sadržaj - $U$ ovom radu razrađen je projekat $A B$ zgrade prema Evrokod propisima. Urađen je kompletan statički proračun, dimenzionisanje $i$ planovi armature. Drugi dio rada odnosi se na proračun prslina sa analizom rezultata prema „EN 1992 “ $i, P B A B$ '87“.

Ključne reči: Višespratna zgrada, statički proračun, dimenzionisanje, planovi oplate $i$ armature, proračun prslina

Abstract - In this thesis it's elaborated the project of the $A B$ building according to Eurocode regulations. A complete static calculation, sizing and reinforcement plans were done. The second part of the thesis deals with the calculation of cracks with the analysis of results according to "EN 1992" and "PBAB '87".

Keywords: Multi-storey building, static analysis, design, formwork and reinforcement plans, cracking

\section{UVOD}

Projektnim zadatkom je predviđeno projektovanje stambenog objekta na teritoriji opštine Novi Sad, spratnosti podrum + prizemlje +6 spratova $(\mathrm{Po}+\mathrm{P}+6 \mathrm{~S})$.

Osnova zgrade je pravougaonog oblika dimenzija $28,5 \mathrm{x}$ $19,5 \mathrm{~m}$, te ukupna bruto površina osnove, uključujući stepenište i hodnike iznosi 555,75 m2.

\section{TEHNIČKI OPIS}

Spratna visina podruma je 4,0 m, dok je ostalih etaža 2,8 m. Objekat je ukopan na kotu $-3,5 \mathrm{~m}$, a kota prizemlja se nalazi na $0,5 \mathrm{~m}$.

Podrumski prostor je predviđen za garaže za automobile. Prizemlje i svih 6 spratova namjenjeno je za stambeni smještaj.

Vertikalna komunikacija se obezbeđuje dvokrakim stepeništem, kojim je predviđen izlazak na ravan krov objekta, i liftom kojim se omogućuje vertikalna komunikacija od podruma do posljednjeg sprata. Stepenište je pozicionirano oko lifta. Dimenzije lift okna u osnovi iznose $1,8 \times 2,1 \mathrm{~m}$.

\section{NAPOMENA:}

Ovaj rad proistekao je iz master rada čiji mentor je bio dr Đorđe Lađinović, red.prof.
$\mathrm{Na}$ slici 1 prikazana je osnova tipske etaže predmetne konstrukcije.

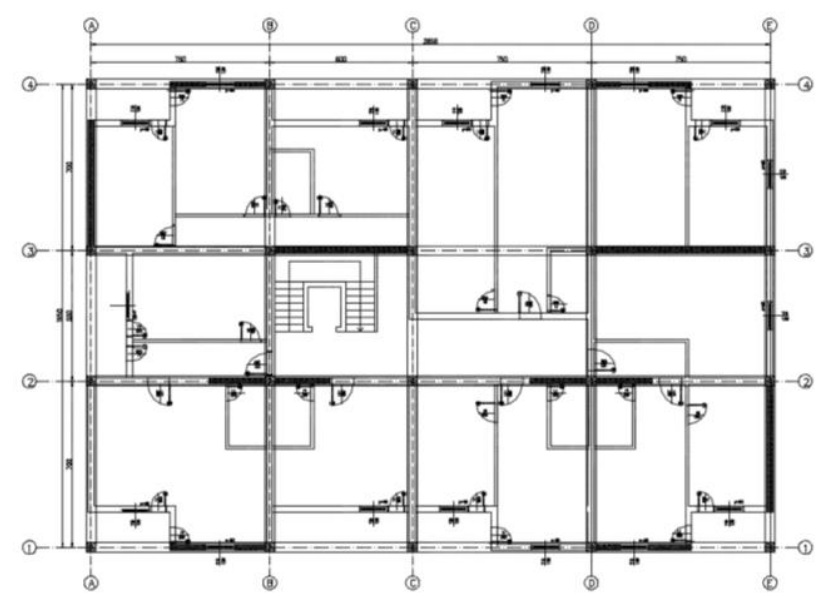

Slika 1. Osnova tipske etaže objekta

\subsection{Konstruktivni sistem objekta}

Konstrukcija objekta je ukrućeni armiranobetonski skelet sa punim međuspratnim AB pločama koje su oslonjene na grede koje se pružaju u dva međusobno upravna pravca. Podrum je oivičen $\mathrm{AB}$ zidovima debljine $25 \mathrm{~cm}$, koji formiraju tzv. „kadu“, tj. kruto AB jezgro i služe za prijem horizontalnog pritiska od tla.

Objekat je temeljen na ploči ukrućenoj gredama koje se pružaju u dva upravna pravca.

Klasa betona za sve armiranobetonske elemente je C30/37, a armature B500B.

Stubovi su promjenljive dimenzije po spratovima, i zastupljena su tri seta stubova. U prve tri etaže stubovi su dimenzija $60 \times 60 \mathrm{~cm}$, u sljedeće tri etaže su $50 \times 50 \mathrm{~cm}$, dok su dimenzije stubova u posljednje dvije etaže $40 \times 40 \mathrm{~cm}$ (18 kom po etaži) i 50x50 cm (2 kom po etaži). Grede zajedno sa stubovima čine dio ramovske konstrukcije. Dimenzije greda su konstantne na svim etažama i iznose $40 \times 65 \mathrm{~cm}$.

Međuspratna konstrukcija je ortotropna armiranobetonska puna ploča debljine $20 \mathrm{~cm}$ na svim etažama.

Temeljnu konstrukciju čini puna armiranobetonska ploča debljine $40 \mathrm{~cm}$ ukrućena gredama dimenzija 50x140 cm. Temeljna ploča je proširena van gabarita objekta za $1,2 \mathrm{~m}$ sa svake strane kako bi se povećala kontaktna površina, te smanjili naponi u tlu. Interakcija tlo-konstrukcija su ostvarene idealizovanjem tla ,Vinklerovim“ modelom. 
Zidovi za ukrućenje se prostiru cijelom visinom objekta i postavljeni su u ose 1, 2, 3, 4, A i E. Debljine su $25 \mathrm{~cm}$. Konstrukcija stepeništa je projektovana kao puna $A B$ koljenasta ploča debljine $15 \mathrm{~cm}$, koja je uklještena u $A B$ zid za ukrućenje. Formirano je kao dvokrako stepenište sa jednim međupodestom na polovini spratne visine. Širina stepeništa je 1,2 m, dok su gazišta dimenzija 17,5x30 cm.

\section{MODELIRANJE KONSTRUKCIJE}

Za modeliranje konstrukcije korišćen je program „Tower 7.0“. Proračun je sproveden primjenom metode konačnih elemenata koja se zasniva na diskretizaciji, te realnu konstrukciju opisuje elementima konačnih dimenzija. Statički uticaji se računaju primjenom linearne teorije elastičnosti, tj. teoriji prvog reda.

Na slici 2 prikazan je 3D model predmetne konstrukcije.

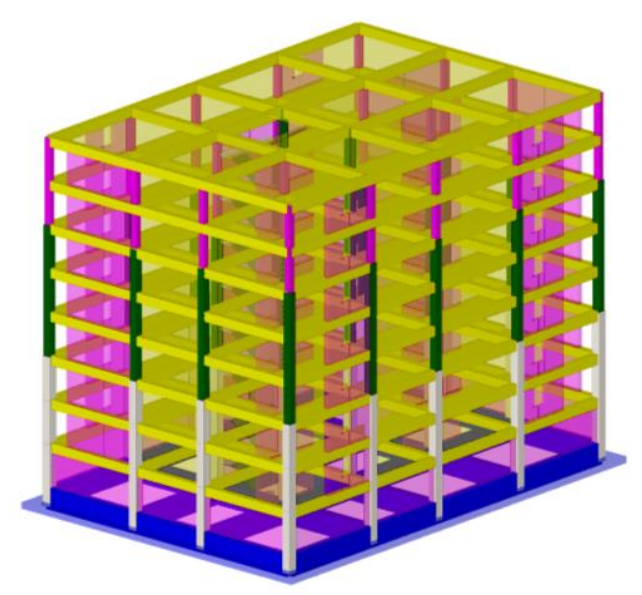

Slika 2. 3D model konstrukcije

Mreža konačnih elemenata kod površinskih elemenata formirana je automatski, uglavnom od četvorougaonih konačnih elemenata sa veličinom konačnog elementa od $0.5 \mathrm{~m}$.

Minimalna debljina međuspratnih tavanica je određena iz uslova zadovoljenja graničnog stanja ugiba preko graničnog odnosa $l / d$, gdje $l$ predstavlja raspon, a $d$ statičku visinu, prema sljedećem izrazu:

$l / d=\left\{\begin{array}{c}K *\left[11+1,5 * \sqrt{f_{c k}} * \frac{\rho_{0}}{\rho}+3,2 * \sqrt{f_{c k}} *\left(\frac{\rho_{0}}{\rho}-1\right)^{1,5}\right] \\ \text { за } \rho \leq \rho_{0}=\sqrt{f_{c k}} * 10^{-3} \\ K *\left[\begin{array}{c}\left.11+1,5 * \sqrt{f_{c k}} * \frac{\rho_{0}}{\rho-\rho^{\prime}}+\frac{1}{2} * \sqrt{f_{c k}} * \sqrt{\frac{\rho^{\prime}}{\rho_{0}}}\right] \\ \text { за } \rho>\rho_{0}=\sqrt{f_{c k}} * 10^{-3}\end{array}\right.\end{array}\right.$

Iz ovog uslova usvojena je visina ploče, $h=20 \mathrm{~cm}$. Računata je po teoriji tankih ploča i prenosi opterećenje $u$ dva pravca.

Ploče stepeništa prenose opterećenje $u$ jednom pravcu i modelirane su kao ortotropne ploče. Kose ploče su oslonjene na kraćim stranama, dok su ravne ploče (međupodesti) uklještene na jednoj dužoj strani. Pretpostavljena debljina armirano betonskih zidova u podrumu, kao i seizmičkih zidova na ostalim etažama je $25 \mathrm{~cm}$.

Grede i stubovi su modelirani linijskim konačnim elementima. Linijski elementi su dimenzionisani prema graničnom stanju nosivosti, pa je torziona krutost greda, zbog pojave prslina, 10 puta manja od torzione krutosti homogenog betonskog presijeka, tj. grede su modelirane sa 10 puta manjim momentom inercije oko ose 1 .

Vinklerov model je korišćen za interakciju konstrukcije i tla. Pretpostavljena vrijednost modula reakcije tla je $20.000 \mathrm{kN} / \mathrm{m}^{2} / \mathrm{m} \mathrm{u}$ vertikalnom pravcu, dok je vrijednost u horizontalnom pravcu $100.000 \mathrm{kN} / \mathrm{m}^{2} / \mathrm{m}$.

\section{ANALIZA OPTEREĆENJA}

Razmatrana su sljedeća opterećenja koja djeluju na predmetnu konstrukciju:

1. Stalno opterećenje (sopstvena težina konstruktivnih i nekonstruktivnih elemenata i opterećenje tlom),

2. Promjenljivo opterećenje:

- $\quad$ korisno, definisano prema Evrokodu 1 [1]

- $\quad$ snijeg, definisano prema Evrokodu 1 [2] i

- $\quad$ vjetar, definisano prema Evrokodu 1 [3]

3. Seizmičko opterećenje, definisano prema Evrokodu 8 [4]

\subsection{Seizmičko opterećenje}

Postoje dvije metode analize seizmičkog dejstva:

- Metoda ekvivalentnih bočnih sila

- Multimodalna spektralna analiza

Koja od navedenih metoda će se koristiti zavisi od regularnosti objekta u osnovi i po visini što je propisano $u$ Evrokodu 8 [4]. Za ovaj rad usvojena je multimodalna spektralna analiza i klasa duktilnosti DCM (srednja klasa duktilnosti). Objekat se nalazi na tlu C kategorije.

Maksimalno ubrzanje tla, u projektovanju, se određuje očitavanjem njegove vrijednosti sa karte seizmičkog hazarda koja je izrađena za povratni period od 475 godina. U ovom slučaju, maskimalno ubrzanje je zadato projektnim zadatkom i iznosi $0,15 \mathrm{~g}$.

Faktor ponašanja se određuje kao proizvod osnovne vrijednosti faktora ponašanja, $\mathrm{q}_{0}$, $\mathrm{i}$ faktora $\mathrm{k}_{\mathrm{w}}$ kojim se obuhvata preovladavajuća vrsta loma konstrukcijskih sistema sa zidovima.

Faktor ponašanja za X i Y pravac iznosi 3,90.

\section{DIMENZIONISANJE}

Prema Evrokod normama, proračun armiranobetonskih konstrukcija se zasniva na teoriji graničnih stanja. Proračunom prema teoriji graničnog stanja se dokazuje sigurnost, trajnost i funkcionalnost konstrukcije. Granična stanja klasifikujemo na:

- Granično stanje nosivosti - lom (GSN)

- $\quad$ Granično stanje upotrebljivosti (GSU)

Ploče su armirane proračunskom armaturom u dva pravca jer prenose opterećenje u dva pravca. Armiranje gornje i donje zone je nezavisno, bez povijanja armature iz jedne zone u drugu.

Minimalna armatura u pločama koja je potrebna kako bi se ploče obezbijedile od krtog loma propisana je Evrokodom 2 [5]:

$$
\mathrm{A}_{s, \min }=0,26 * \frac{f_{c t m}}{f_{y k}} * d * b
$$

Dimenzionisanje linijskih elemenata (grede i stubovi) je međusobno uslovljeno. Prvo se dimenzionišu grede i usvaja se podužna armatura, nakon čega se usvaja podužna armatura u stubovima. $\mathrm{Na}$ kraju se usvaja poprečna armatura greda, a zatim i poprečna armatura stubova. 
Kada se zid dimenzioniše na složeno savijanje, mjerodavni uticaji su $\mathrm{M}$ i $\mathrm{N}$ a za prijem smičućih naprezanja mjerodavni su uticaji $\mathrm{T}$.

Armiranje se sprovodi tako što se izabere minimalno potrebna vertikalna podužna armatura $u$ rebru i horizontalna podužna armatura za prijem napona smicanja. Ostatak uticaja koje ne pokriva minimalna armatura se pokrivaju ugaonom armaturom simetrično raspoređenom.

\section{KONTROLA PRSLINA}

Cilj istraživanja je da se predstavi razlika rezultata između dva standarda od kojih je jedan prestao da važi (,PBAB '87“), a drugi je trenutno važeći (,EN 1992“).

Osnovni razlog pojave prslina je relativno niska čvrstoća betona pri zatezanju.

Najraniji period u kom prsline mogu da se pojave je u fazi građenja, kada se mogu pojaviti još prije očvršćavanja betona. Razlog njihove pojave može biti nepravilno spravljanje, ugrađivanje i njegovanje betona. Prsline nastaju usljed plastičnog sleganja, plastičnog skupljanja, hidratacije cementa, spriječenog slobodnog dilatiranja.

Na slikama 3, 4, 5 i 6 su prikazane prsline u elementima konstrukcije u zavisnosti od vrste uticaja.
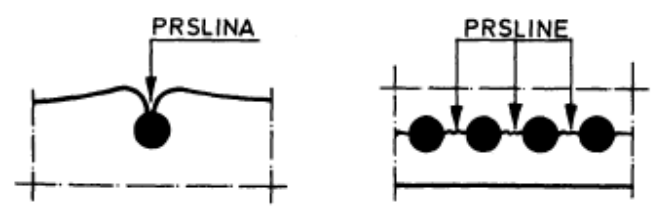

Slika 3. Prsline usljed plastičnog sleganja: iznad šipki $i$ između gusto raspoređenih šipki [6]
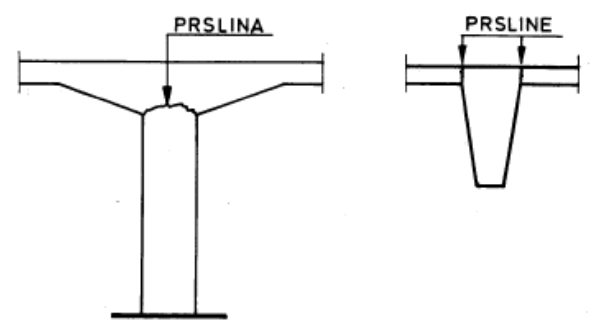

Slika 4. Prsline usljed plastičnog sleganja kao posljedica nagle promijene geometrije AB elementa [6]
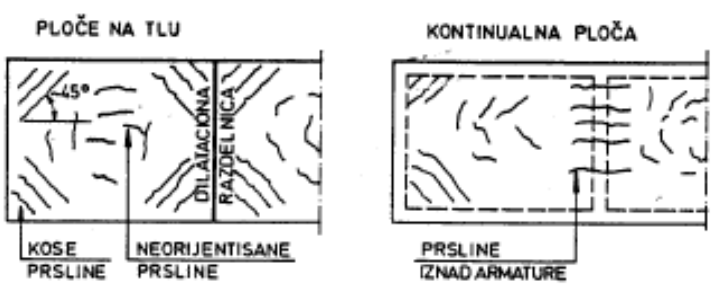

Slika 5. Prsline usljed plastičnog skupljanja betona [6]

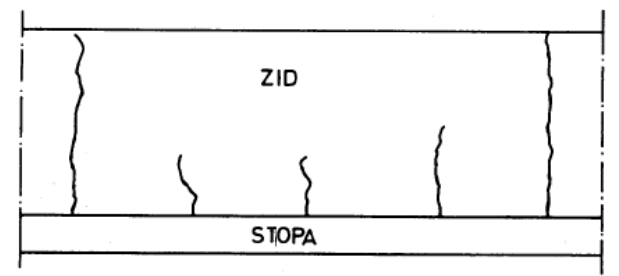

Slika 6. Prsline usljed spriječenog temperaturnog dilatiranja [6]

\subsection{Proračun prslina prema „PBAB ' $87^{6}$}

Proračun prema graničnom stanju prslina zahtijeva dokaz da karakteristična širina prslina $\mathrm{a}_{k}(t)$ za najnepovoljniju kombinaciju dejstava $\mathrm{u}$ toku eksploatacije, $\mathrm{u}$ proizvoljnom trenutvku vremena $(\mathrm{t})$ ne prelazi graničnu vrijednost prslina $\mathrm{a}_{u}$ (tabela 1 ):

$$
\mathrm{a}_{k}(t) \leq \mathrm{a}_{u}
$$

Tabela 1. Granične vrednosti širine prslina $\left(\mathrm{a}_{u}\right)$ [6]

\begin{tabular}{|c|c|c|}
\hline \multirow[b]{2}{*}{$\begin{array}{l}\text { Agresivnost } \\
\text { sredine }\end{array}$} & \multicolumn{2}{|c|}{ Trajanje uticaja } \\
\hline & $\begin{array}{c}\text { stalno i dugotrajno } \\
\text { promenljivo }\end{array}$ & $\begin{array}{c}\text { stalno, dugotrajno } \\
\text { i kratkotrajno } \\
\text { promenljivo }\end{array}$ \\
\hline Slaba & 0,2 & 0,4 \\
\hline Srednja & 0,1 & 0,2 \\
\hline Jaka & 0,05 & 0,1 \\
\hline
\end{tabular}

Karakterističična širina prslina $\mathrm{a}_{k}(t)$ definiše se kao vrijednost koja je za $70 \%$ veća od vrijednosti srednje širine prslina $\mathrm{a}_{s}(t)$.

$$
\mathrm{a}_{k}(t)=1,7 \mathrm{a}_{s}(t)
$$

Srednja širina prslina $\mathrm{a}_{s}(t)$, $\mathrm{u}$ trenutku vremena $\mathrm{t}$, predstavlja izduženje koje odgovara srednjem rastojanju prslina $l_{p s}$ i relativnoj srednjoj dilataciji donje zategnute armature $\varepsilon_{a 1 s, R}(t)<0$, u odnosu na zategnuti beton $\mathrm{u}$ njenoj neposrednoj okolini:

$$
\mathrm{a}_{s}(t)=l_{p s}\left[-\varepsilon_{a 1 s, R}(t)+\varepsilon_{b}\left(t, t_{0}\right)\right]
$$

Eksperimentalna ispitivanja pokazuju da srednje rastojanje prslina $l_{p s}$ zavisi od efektivne površine zategnutog betona $A_{b z, e f}$, na koju se naponi zatezanja $\mathrm{u}$ betonu između susjednih prslina stvarno mogu prenijeti.

$$
l_{p s}=2\left(a_{0}+\frac{e_{\phi}}{10}\right)+k_{1} k_{2} \frac{\phi}{\mu_{1 z, e f}}
$$

\subsection{Proračun prslina prema ,EN 1992“}

U zavisnosti od klase izloženosti elementa konstrukcije/objekta, tabelom 2 koja je data propisom Evokod 2 [5], prikazane su granične vrijednosti računske

\begin{tabular}{|c|c|c|}
\hline Klasa izloženosti & $\begin{array}{c}\text { Armiranobetonski i prethodno } \\
\text { napregnuti elementi sa kablovima } \\
\text { bez prianjanja sa betonom }\end{array}$ & $\begin{array}{l}\text { Prethodno napregnuti elementi sa } \\
\text { kablovima sa prianjanjem }\end{array}$ \\
\hline & Kvazi-stalna kombinacija opterećenja & Česta kombinacija opterećenja \\
\hline $\mathrm{x} 0, \mathrm{xC1}$ & $0,4^{1}$ & 0,2 \\
\hline $\mathrm{xC2}, \mathrm{XC} 3, \mathrm{XC} 4$ & \multirow{2}{*}{0,3} & $0,2^{2}$ \\
\hline $\begin{array}{l}\text { XD1, XD2, Xs1, } \\
\text { XS2, XS3 }\end{array}$ & & dekompresija \\
\hline \multicolumn{3}{|c|}{$\begin{array}{l}\text { Napomena 1: Za klase izloženosti XO, XC1, širina prsline nema uticaja na trajnost i to ograničenje } \\
\text { treba samo da obezbedi prihvatljiv izgled konstrukcije. Ako nema uslova koji se odnose na izgled ovo } \\
\text { ograničenje može da se ublaži } \\
\text { Napomena 2: Za te klase izloženosti, osim toga, treba da se proveri i dekompresija za kvazi-stalnu } \\
\text { kombinaciju opterecenja. }\end{array}$} \\
\hline
\end{tabular}
širine prslina, $W_{\max }$ kojih je se potrebno pridržavati prilikom proračuna prslina.

Tabela 2. Granične vriednosti širine prslina $\left(W_{\max }\right)$ [5]

Donji dio konstrukcije pripada XC1 klasi izloženosti. Prsline u temeljnoj gredi ograničene su na $0,4 \mathrm{~cm}$.

Ostatak konstrukcije pripada klasama XC3 i XC4, te su širine prslina ograničene na $0,3 \mathrm{~cm}$.

U zonama u kojima se očekuje pojava prslina, potrebno je usvojiti bar minimalnu površinu armature sa prijanjanjem sa betonom. Minimalna površina armature određuje se prema sledećem izrazu:

$$
\mathrm{A}_{s, \text { min }} * \sigma_{s}=k_{c} * k * f_{c t, e f f} * A_{c t}
$$


Karakteristična širina prslina računa se prema sledećem izrazu:

$$
W_{k}=S_{r, \max }\left(e_{s m}-e_{c m}\right)
$$

$S_{r, \text { max }}$ - maksimalno rastojanje između susjednih prslina

$$
S_{r, \max }=k_{3} c+k_{1} k_{2} k_{4} * \phi / \rho_{p, e f f}
$$

$e_{s m}-e_{c m}$ - razlika između srednje dilatacije armature za mjerodavnu kombinaciju opterećenja uključujući uticaj prinudnih deformacija i sadejstvo zategnutog betona $\mathrm{i}$ srednje vrijednosti dilatacija u betonu između prslina:

$e_{s m}-e_{c m}=\frac{\sigma_{s}-k_{t} \frac{f_{c t, e f f}}{\rho_{p, e f f}}\left(1-\alpha_{e} \rho_{p, e f f}\right)}{E_{s}} \geq 0,6 \frac{\sigma_{s}}{E_{s}}$

Proračun širine prslina može da se uprosti i prikaže u obliku tabela, gdje su date granične vrijednosti prečnika ili rastojanja šipki, što je definisano u Evrokodu 2 [5].

\subsection{Uporedna analiza rezultata}

Karakteristična vrijednost širine prslina u većini presijeka veća je u slučaju proračuna prema „PBAB 87 “, što može da se vidi na slici 7. Jedan od razloga su strožiji zahtijevi po pitanju kombinacija opterećenja kod proračuna karakteristične širine prslina prema propisu „PBAB 87“. $\mathrm{Za}$ izbor kombinacije, opterećenja za proračn prslina, koeficijenti uz slučajeve opterećenja jednaki su jedinici. Dok se kod proračuna prslina prema „EN 1992“ koristi kvazi-stalna kombinacija opterećenja sa koeficijentima $\psi_{2}$ koji su manji od jedinice, što dovodi i do manjih uticaja, a samim tim i manjih prslina.

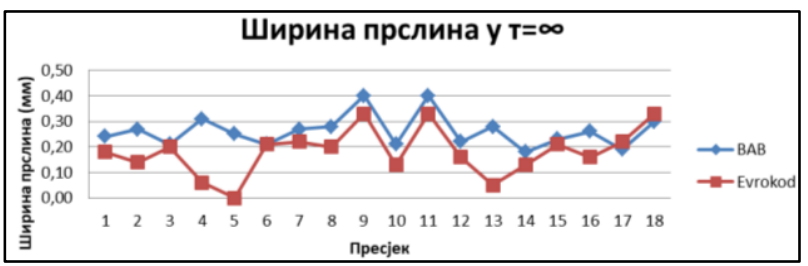

Slika 7. Dijagram širina prslina

Rastojanje između prslina zavisi od veličine zaštitnog sloja betona, učešća vrste armature, prečnika podužne armature, vrste naprezanja, i koeficijenta armiranja efektivne zategnute zone.

Rastojanje između dvije susjedne prsline prema ovom ispitivanju u većini presijeka veća je kod proračuna prema „EN 1992“. Ova razlika može se opravdati različitim koeficijentima armiranja. Proračun prema „EN 1992“ zahtijeva manju količinu armature.

$\mathrm{Na}$ slici 8 prikazan je dijagram sa uporednim rezultatima širina između prslina.

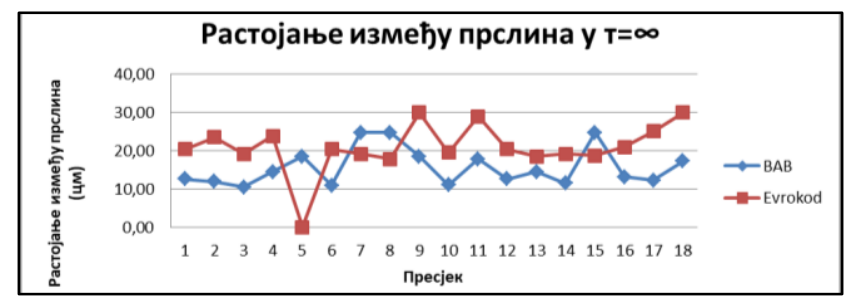

Slika 8. Dijagram rastojanja između prslina

\section{ZAKLJUČAK}

Dobijeni rezultati se razlikuju, kako karakteristična vrijednost širine prslina, tako i rastojanje između dvije susjedne prsline iako je postupak proračuna širine prslina i rastojanja između prslina prema dva pravilnika dosta sličan.

„PBAB 87“ kao stariji i u ovom segmentu proračuna komplikovaniji standard, daje veće vrijednosti širina prslina u odnosu na novi standard.

„EN 1992“ kao mlađi standard teži uprošćavanju proračuna prslina. Ovaj standard je strožiji po pitanju rastojanja između prslina u osnosu na stari standard.

Minimalna armatura je osnovni uslov za održavanje širina i rastojanja između prslina u dozvoljenim granicama. Preporuka je obezbijediti bar minimalnu količinu armature u svakom presijeku, te usvajati više šipki manjeg prečnika, nego manje šipki većeg prečnika.

\section{LITERATURA}

[1] EN 1991-1-1:2002-Evrokod 1 „Dejstva na konstrukcije“", Beograd, novembar 2009.

[2] EN 1991-1-3:2003-Evrokod 1 „Dejstva na konstrukcije“, Beograd, novembar 2009.

[3] EN 1991-1-4:2005-Evrokod 1 „Dejstva na konstrukcije“, Beograd, novembar 2009.

[4] EN 1998-1:2004-Evrokod 8 „Proračun seizmički otpornih konstrukcija“, Beograd, novembar 2009.

[5] EN 1992-1-1:2004-Evrokod 2 „Proračun betonskih konstrukcija“, Beograd, februar 2006.

[6] Beton i armirani beton, Knjiga 1 "Osnove proračuna i konstruisanja“, Beograd, 2000.

[7] Zoran Brujić: "Betonske konstrukcije u zgradarstvu (prema Evrokodu)-skripta“, Novi Sad, 2018.

\section{Kratka biografija:}

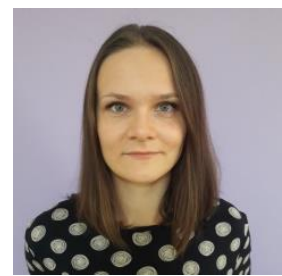

Dragana Nerić rođena je na Sokocu 1994. god. Master rad na Fakultetu tehničkih nauka iz oblasti - Seizmička analiza konstrukcija odbranila je 2019. godine.

kontakt:dragana_neric@hotmail.com 